\section{THE ADVENT OF THE AIRCRAFT GAS TURBINE*}

\section{BY AIR Commodore F. WHITTLE, C.B.E.}

\section{International Standard Atmosphere}

$\mathrm{T}$ HE properties of what is known as the "International Standard Atmosphere" for the temperate zone are shown in Fig. I. At 20,000 ft. the density is a little more than half its sea-level value, and at $40,000 \mathrm{ft}$. it is just under one-quarter. The temperature drops almost $2^{\circ}$ per $1,000 \mathrm{ft}$. up to just over $36,000 \mathrm{ft}$. and then it remains constant. A curve for pressure variation is not included but it is very similar to that for density, though the density does not fall off quite so rapidly as pressure because of the reduction in temperature. In the stratosphere, that is, above $36,000 \mathrm{ft}$. , the temperature being constant, pressure is proportional to density. 'The reduction of temperature with height is of great importance from the gas turbine point of view. As I shall explain later, the lower the temperature the greater the efficiency for given maximum combustion temperatures.

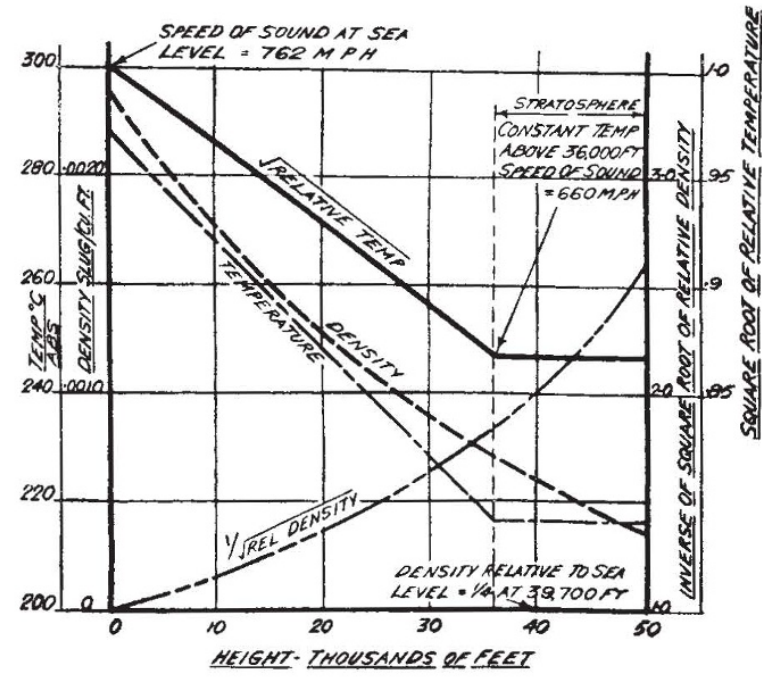

Fig. 1. International Standard Ammosphere.

The reduction of temperature is also important because of its effect on the speed of sound. The curve showing the relation between the square root of the relative temperature and height corresponds to the change of the speed of sound with height because the speed of sound is proportional to the square root of the absolute temperature. At sea-level it is $762 \mathrm{~m} . \mathrm{p} . \mathrm{h}$. and at $36,000 \mathrm{ft}$. and upwards it is 660 m.p.h. As is now well known, when an aeroplane reaches speeds approaching that of sound there is a sharp rise in drag coefficient due to the effects of compressibility. Similarly, there is apt to be trouble with engine parts moving at high speed when the relative velocities approach the speed of sound.

The curve showing the variation of the inverse of the square root of relative density gives the ratio of true air speed to indicated air speed at any height. The air-speed indicator is really a differential pressure gauge which is responsive to the dynamic pressure due to forward speed; but the dial is graduated to give speed readings in accordance with the relationship

* From a Royal Institution discourse delivered on December 7. which holds good between speed and dynamie pressure at sea-level. All the forces on the aeroplane such as drag and lift are functions of dynamic pressure. If the instrument indicates (say) 300 m.p.h., then it means that the dynamic pressure is that corresponding to 300 m.p.h. at sea-level, but at heights above sea. level the true speed is greater than the indicated speed. Thus, if the air-speed indicator records $250 \mathrm{~m} . \mathrm{p} . \mathrm{h}$. at a height when the relative density is one-quarter, then the true air speed is 500 m.p.h., but the lift and drag forces, etc., are those corresponding to $250 \mathrm{~m} . \mathrm{p} . \mathrm{h}$. at sea-level. This relationship holds good so long as the true speed is not high enough for compressibility effects to be important.

\section{Drag}

The resistance or drag of an aeroplane has two primary constituents. One, known as the induced drag, is the penalty paid for lift ; it would be zero with a wing of infinite span. It varies inversely as the dynamic pressure. At high indicated air speeds it becomes very small. The other major component of drag is known as profile drag. By this is usually meant the sum of skin friction drag and form drag. It is approximately proportional to the dynamic pressure up to speeds at which compressibility effects begin to become pronounced and then it increases much more rapidly. Since dynamic pressure is proportional to the square of the indicated air speed, part of the drag varies inversely as the square of the indicated speed and the other part varies directly as the square of the indicated speed; and it can easily be shown that total drag is a minimum when the two components of drag are equal.

At the speed of minimum drag the least work has to be done in covering a given distance, so that it is obviously the speed of maximum range assuming a given efficiency of propelling power plant. At or near sea-level, the speed of minimum drag is not very much greater than the landing speed; but though the drag is a minimum at a given indicated air speed at all heights, it can correspond to very high true speeds at great heights. Thus, if the drag of an aeroplane were a minimum of 1,000 lb. at 150 m.p.h. at sea-level, it would be the same minimum of $1,000 \mathrm{lb}$. at an indicated air speed of 150 m.p.h. at all heights, but at (say) 40,000 ft. the corresponding true speed would be 302 m.p.h. Note that the minimum work which has to be done in covering a given distance is unchanged by height; that is, for constant efficiency of power plant, height does not allow an increase of maximum range. Note also that in the example given, just over twice as much power would be required for the speed of minimum drag at $40,000 \mathrm{ft}$. as compared with the sea-level case ; against that, of course, the distance is covered in half the time.

\section{Piston Engine/Propeller Combination}

In the familiar piston engine and propeller combination, the propeller is essentially a device for inducing an increase of rearward momentum in a stream of air; in other words, it is a form of jet propulsion.

The efficiency of a propeller has two main com. ponents, namely, the fan efficiency and the Froude efficiency. Its fan efficiency is its efficiency as a device for turning the shaft power supplied to it into an increase of kinetic energy in a sternwards direction. This fan efficiency is usually more than 90 per cent, so long as the speed of the propeller tips is not too near the speed of sound. One of the obvious losses is the 
rotational component of the slipstream, which contributes nothing to the propulsive thrust.

The thrust is proportional to the rate of change of momentum induced in the axial direction. The rate of doing useful work in propulsion is the product of thrust and the speed of the aircraft; this is always less than the energy expended in generating sternwards kinetic energy in the air engaged by the propeller. The ratio of the rate of doing useful work to the rate of generation of increased sternwards kinetic energy is the Froude efficiency. It can easily be shown that for high Froude efficiency it is better to obtain a given thrust by inducing a small increase of velocity in a large mass of air than by inducing a large increase of velocity in a small mass of air ; in fact, the formula for Froude efficiency is given by

$\frac{2}{r+1}$, where $r$ is the ratio of jet velocity to forward velocity.

Of course, the velocity of portions of the propeller blade relative to the air is greater than the forward speed of the aeroplane because of the rotation of the propeller ; so that at high forward speeds we run into compressibility troubles because the rotational velocity at the tip is itself of the order of the speed of sound. For this reason there is a severe fall-off in propeller efficiency at high forward speeds.

With tractor propellers, a factor which has to be borne in mind is that the drag of the aeroplane swept by the slipstream is increased, partly because of the increased velocity and partly because the disturbance in the slipstream causes an early transition in the boundary layer from a low-drag laminar layer to a high-drag turbulent layer. The increase of drag due to slipstream would be much reduced by the use of pusher propellers; and no doubt when certain of the mechanical difficulties attached to the use of pusher propellers have been overcome they will become much more in evidence than they are at present.

Power-Plant Weight and Fuel Consumption

A very important point is illustrated in Fig. 2, namely, that a large proportion of the aeroplane is there to carry the power plant and fuel. Comparisons between different kinds of power plant are often made on the basis of thermal efficiency or fuel consumption per unit power, etc.; but in an aeroplane this is a totally false basis of comparison. It is easily possible that for aeroplanes to perform certain tasks the fuel consumption expressed in terms of power for one power plant may be substantially higher than another, and yet because the apparently less efficient power plant may make an altogether smaller aeroplane possible for the given duty, it may be more efficient when the fuel consumption is measured in terms of ton-miles of useful payload.
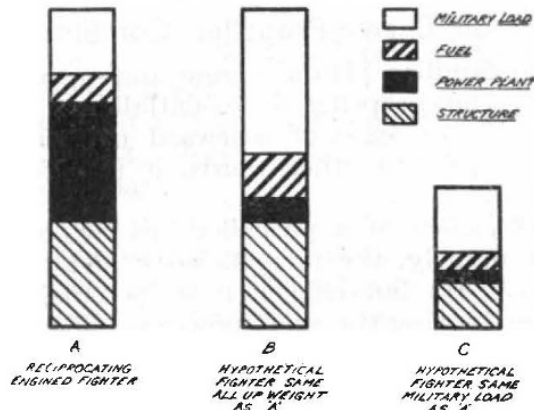

W sturner

Fig. 2. WEIGHT DISTRIBUTION OF FIGHTERS (SAME SPEED AND
RNDURANCE).
At $A$ is illustrated the approximate weight distribution of a modern fighter with petrol engine and propeller. The military load including pilot is 20 per cent, the power plant and fuel accounts for 47 per cent -37 per cent to the power plant and 10 per cent to the fuel. Structure weight represents 33 per cent. But of course part of the structure weight is debitable to power plant and fuel, so that some 70 per cent of the total weight is directly or indirectly attributable to power plant.

Diagram $B$ illustrates the weight distribution of a hypothetical aeroplane for the same speed and endurance at the same height, having a hypothetical power plant which consumes about 50 per cent more fuel in proportion to power, but which is only onefifth the weight in proportion to power. In the second case the amount of fuel is 50 per cent greater than in the first, but the military load is 127 per cent greater. $C$ shows the reduction in size we get if we make our hypothetical aeroplane to carry the same military load. In the second case the payload/fuel ratio is about 50 per cent better than the first. A short-range aeroplane of high performance illustrates this point. For greater ranges things move in favour of the heavier power plant with the lower fuel consumption; but I hope I have made it clear that a comparison between two power plants should not be made without reference to the duty which the aeroplane has to perform.

\section{Campini System}

The Campini system of propulsion consists of an internal combustion engine driving a low-lift com pressor within a large diameter duct, either in a fuselage or a nacelle. The function of the low-lift compressor (or 'ducted fan' as it is often called) is the same as a propeller, namely, to impart increased kinetic energy in a rearwards direction.

The Italians claim to have flown with this system in 1940, but the results were so disappointing that the scheme was dropped. It is difficult to see why they ever thought it worth while, because nothing is saved in power-plant weight as compared with the normal piston engine and propeller combination, while the mass of air which the fan can engage is so much lower than that of a propeller that the Froude efficiency is inevitably very much lower. The most that can be claimed in favour of it is an absence of slipstream over the external surfaces, shorter undercarriage, etc., and that the heat from the engine exhaust, etc., which would otherwise be wasted can be recovered to a small extent because it is discharged into air at a pressure a little above atmospheric.

\section{The Impulse Duct}

The propulsive system of the flying bomb is what is known as an impulse duct and is extremely simple. In front of the duct there is a grid of automatic leaf. spring flap valves. Petrol is injected into the duct immediately behind these valves and a series of explosions takes place at a frequency depending on the dimensions of the duct. As the pressure in the duct drops below the ram pressure the leaf springs open and admit a fresh charge of air and are closed again by the succeeding explosion. Propulsion is thus in effect produced by a series of backfires. In common with the propeller, the Campini system, and the turbojet system to be described below, the device produces a thrust because it takes air in at the front and expels it to the rear with increased velocity. The thrust, of course, fluctuates considerably. 
The fuel consumption is very high, though powerplant weight is very small. For the purpose for which it was designed, namely, the pilotless bombing of a very large area at a range of the order of 150 miles, nobody can deny that it was very effective.

\section{The ME. 163 (Bi-Fuel Rocket System)}

The bi-fuel rocket systern was developed intensively by the Germans, as in the Me. 163 interceptor fighter. Both the fuel and the oxygen required for combustion have to be carried in the aeroplane, consequently the amount of expendable material which has to be carried for a flight of even short duration is very great. This system differs from others in that it does not draw in air from the atmosphere. In the devices propelled in this way, the Germans used hydrocarbon fuel and either liquid oxygen or a substance rich in oxygen such as hydrogen peroxide or nitric acid. The thrust per unit mass flow of the bi-fuel rocket system varies, of course, with the fuel constituents, but is usually between 160 and $200 \mathrm{lb}$./lb./sec. This system of propulsion can give very high performance for a very short time.

\section{The Turbo-Jet System}

The turbo-jet system of propulsion (Fig. 3) brings us to the gas turbine. Air is taken in at the front and compressed into a combustion chamber by a compressor. In the combustion chamber it is heated at constant pressure. It then expands through a turbine to an extent sufficient to drive the compressor. Final expansion then takes place through the propelling nozzle. It works on the constant-pressure cycle illustrated in the pressure-volume diagram shown (Fig. 4). $A-B$ represents the compression due to ram pressure, $B-C$ the further compression in the compressor, $C-D$ the combustion at constant pressure, $D-E$ that portion of the expansion through the turbine necessary to drive the compressor, $E-F$ the final expansion which provides the kinetic energy of the propelling jet.

About 1920-30 the many failures in attempts to produce a successful gas turbine had led to a general pessimism in the engineering world. There was a curious tendency to believe that materials of sufficiently high stress-temperature properties would not become available, and that the comparatively low efficiencies of compressors and turbines of that time were inevitable. I believed, on the other hand, that very considerable improvements in component efficiencies were possible, and in the case of the jet propulsion gas turbine I realized that there were certain favourable factors not present in other applications, namely :

(1) The low temperature of high altitudes made possible higher efficiencies for a given maximum cycle temperature and given component efficiencies.

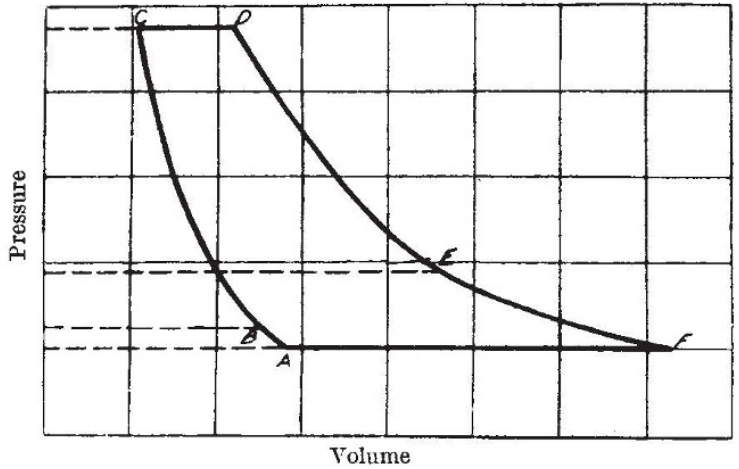

Fig. 4. Crche AT 500 M.P.H. AT SEA-I.eVEL.

(2) Part of the compression could be obtained by the ram effect of forward speed at high efficiency, thereby raising the average efficiency of the whole compression process.

(3) Only sufficient of the expansion took place in the turbine as was necessary to drive the compressor, and therefore only a part of the expansion was subject to turbine losses.

I have already told the story of the early days of the Whittle jet propulsion gas turbine in my James Clayton Lecture before the Institution of Mechanical Engineers, so I will not go into the details now. We started to construct our first experimental engine in 1936 and first ran it in April 1937. As first constructed, it was very unsatisfactory, and we decided to reconstruct, and the second edition was running in April 1938. After severe damage as the result of a turbine failure we decided to reconstruct once more and we had the third edition on test in October 1938. The compressor was a single-stage double-sided centrifugal. It was directly coupled to a single-stage turbine. The air from the compressor was delivered to ten combustion chambers in parallel and the hot products of combustion passed from the combustion chambers through the turbine and out. through the jet pipe and propelling nozzle.

In those days we used a 10 h.p. B.S.A. motor-car engine for starting, but later on we found that it was possible to use a small electric motor. We did in fact succeed in starting up with the starter-motor off the starting engine.

That engine was the parent of a whole family of jet propulsion gas turbines. A flight engine, known as the WI, aerodynamically and thermodynamically similar to the experimental engine, was made. At the same time the Gloster Aircraft Co. made the experimental aeroplane known as the E28/39. Successful flight tests with the WI installed in the E28/39 took place in May 1941.

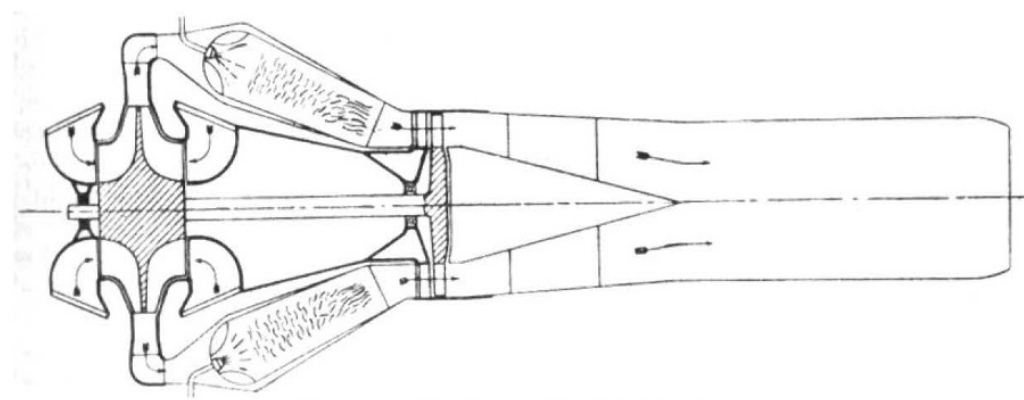

Fig. 3. JET PROPULSION GAS TURBINE.

\section{The Rolls-Royce Derwent $V$}

The Rolls-Royce 'Derwent $V$ ' is the engine with which the world's speed record was recently gained. The effective thrust power of each engine when travelling at 600 miles an hour was of the order of 5,000 , that is, the total effective thrust horse-power of the two engines was about 10,000 . For the ord. inary reciprocating engine and propeller combination to have produced the same thrust power, the effective 
total shaft power would have to have been about 16,700 h.p., for which the fully installed weight would have been of the order of $30,000 \mathrm{lb}$., that is, about twice the weight of the aeroplane. The fully installed weight of the two 'Derwent V's' would be less than $3,000 \mathrm{lb}$., that is, less than 10 per cent of the weight of the conventional power plant, to produce the same effective thrust power. I admit that $I$ have made this weight comparison under conditions least favourable to the conventional power plant, because the power of the latter can be maintained by supercharging to heights of the order of $30,000 \mathrm{ft}$., whereas the power of the turbo-jet engine falls off with height. Com. parisons made at lower speeds would also have been much less favourable to the jet engine, but at least these figures serve to illustrate the point that there is little hope of the conventional power plant competing with the turbo-jet at very high speeds.

The power required to drive the compressor of the Derwent $V$ would be of the order of 120 h.p. per lb. of air flowing through the engine per second. The mass flow would be of the order of $80 \mathrm{lb}$./ $/ \mathrm{sec}$., so that the shaft power produced by the turbine is in the neigh. bourhood of 10,000 . The kinetic energy in the jet is also of the order of $10,000 \mathrm{~h} . \mathrm{p}$.

\section{Materials}

A very important phase in the successful development of aircraft gas turbines has been the evolution of materials capable of withstanding a combination of high stress and high temperature. The lack of such materials in the past was one of the principal obstacles to early experimenters. To some extent a vicious circle was operating. There was little incentive to produce materials which would make gas turbines practicable so long as gas turbines did not exist ; and the non-existence of the materials hindered the evolution of the gas turbine. Fortunately, in the last two decades there have been other stimuli to the development of such materials, one of the chief of these being the need for them in the exhaust valves of piston engines, etc. Another was the need arising out of the use of increasing temperatures and stresses in steam turbines. When we started practical work in 1936, the best material available was Firth-Vickers 'Stayblade'. We used this material for our first turbine disks and blades; it was a ferrous alloy of austenitic type having a high nickel and chromium content. Shortly after, Firth-Vickers produced a much im. proved austenitic steel of the same class known as 'Rex 78', and the use of this material for the turbine blades led to important improvements in performance. Then the Mond Nickel Co. produced a nickel chromium alloy known as 'Nimonic 80', and this has been extensively used recently.

In turbine design we are not so much concerned with the ultimate strength of materials at the working temperatures as with the ereep properties. Under stress at high temperatures, all these materials slowly extend ; this is the process known as 'creep'. For a given stress and temperature there is usually a fairly well-defined rate of ereep. The order of creep-rate which is tolerable in an aircraft gas turbine is about 1 per cent per 1,000 hours.

The improvement in the properties of light alloys, especially aluminium alloys, has also had an important influence on gas turbine development, though properties of light alloys have been by no means as limiting as those of turbine blade materials.

\section{Efficiency of the Turbo Jet Engine}

I have shown earlier that Froude efficiency is very dependent on the ratio of jet speed to forward speed. With these jet engines the jet velocities are of the order of 1,600 to more than $2,000 \mathrm{ft}$. per sec., that is, of the order of three times the forward speed of the aeroplane. Froude efficiency corresponding to a $3: 1$ ratio is 50 per cent, so that the propulsive efficiency is relatively poor, though at speeds of the order of $500 \mathrm{~m}$. p.h. the efficiencies of propellers are dropping to values little more than this. The efficiency of the engine as a heat engine for generating kinetic energy in a jet is about 34 per cent at heights where the temperature is very low, so that the absolute overall efficiency is of the order of 17 per cent.

The absolute efficiency of the piston engine and propeller combination is about 24 per cent at cruising power and moderate speeds, but at high speeds where the peak power has to be obtained by a large degree of supercharging and rich mixtures, and where com. pressibility effects have reduced the propeller efficiency very considerably, the piston engine and propeller combination shows little if any improvement on the jet engine. The jet engine is only a small fraction of the weight of the piston engine and propeller combination, and this, coupled with the fact that a jet aeroplane is intrinsically smaller and cleaner aerodynamically than the more orthodox type, throws the balance heavily in favour of the jet engine for high-performance aircraft such as interceptor fighters and high-altitude mailplanes of moderate range. Anything which is done to reduce aireraft drag brings the turbo-jet system more and more on to the map.

\section{Variation of Power with Height and Speed}

If the air temperature remained constant at all heights, the thrust power of the turbo-jet would be exactly proportional to air density at a given speed; but owing to the increase of efficiency with lower air termperatures, the power for a given speed falls off less rapidly than the density up to the stratosphere. In the stratosphere the temperature is constant and power is therefore proportional to density. The power required for the aeroplane for level flight at a given speed of course falls off, at least until that given speed corresponds to the speed of minimum drag.

With the piston engine and propeller, the thrust falls off rapidly with forward speed in such a way that the effective thrust-power shows only a small variation over a wide speed-range. The turbo jet, on the other hand, gives only a small variation of thrust, and hence the effective thrust-power is nearly proportional to speed.

\section{Gas Turbine/Propeller Combination}

So far the gas turbine has found its main application in aircraft in the ways I have already indicated; but that is not its only use. The turbo-jet system is essentially suitable for high-speed aircraft to cover moderate ranges at heights of the order of $40,000 \mathrm{ft}$. For lower speeds at lower heights and longer range, there is no doubt that the gas turbine will be used to drive a propeller, thus combining the high propulsive efficiency of the propeller with the very low plantweight of the gas turbine. With arrangements of this kind there will usually be some jet thrust, but the greater proportion of the power would be fed to the propeller.

This by no means exhausts the possibilities of gas turbines for use in aircraft. For some duties it seems possible that it would be better to use a gas turbine 
driving a ducted fan, rather on the lines of the Campini system mentioned earlier, though with the piston engine of the Campini system replaced by a gas turbine.

The permutations and combinations possible in gas turbine power plant are endless. The variations possible with the piston engine are limited by the fact that the processes of compression, combustion and expansion take place in the one organ, the cylinder, but in the gas turbine these three processes are carried out in specialized organs. For compression, we can use centrifugal compressors or axial flow compressors, and possibly displacement compressors or various combinations of these. There is a corresponding possible number of variations in the combustion system, and again a large number of variations is possible in the turbine system. Added to all these are the possibilities involved in the use of heat exchangers, the burning of additional fuel between turbine stages, or in the low-pressure air from a ducted fan, and so on. We are as yet only at the very beginning of this field of engineering.

So far it has been the British and American practice to use kerosene as the fuel. It is quite possible to use lower grade fuels so far as the engine is concerned, but they usually have a freezing point in the neighbourhood of $0-10^{\circ}$ C.- an inconvenient property for aircraft which have to be left standing on an airfield in exposed weather conditions. Nevertheless, no doubt lower grade fuels will become more generally used in future.

One great advantage that turbine engines have over normal power plants is almost complete absence of vibration and much reduced noise. These are more important factors than is generally realized. For commercial purposes it will add greatly to passenger comfort. The gain on this account will not be so great with the propeller gas-turbine combination as with the simple jet or ducted fan types. This may be a factor operating strongly in favour of the ducted fan when there is otherwise little to choose between them.

\section{Conclusions}

There is no doubt that the aircraft gas turbine is going to have profound effects on future aircraft development. I predict that in from five to ten years' time we shall see the piston engine displaced in all new aircraft except the light aeroplane. It is possible that the gas turbine will invade that field also; but at present it seems less easy to design for the low power required by light aeroplanes than for much higher power than we are using at present. When I say that the gas turbine will displace the reciprocating engine, I do not mean that it will be substituted for the reciprocating engine in types designed for the latterin fact that is very unlikely, because, among other things, the use of the gas-turbine type of power plant introduces an important new aspect in the aeroplane/engine combination. Power plant and aircraft will have to be designed together. Hitherto it has been the practice to treat them almost independently, but in future one will need to be 'tailor-made' to the other. There will also be much greater variation in types of power plant, depending on the duty the aeroplane has to perform. In fact, the task for which the aeroplane is intended will have to be the starting point for both the engine and the air-frame design.

Another important change of procedure will be required. In the past, it has been the custom to design and develop an engine virtually independently of any particular aircraft, and in advance of the design of the aeroplanes which eventually used them. The usual development time for reciprocating engines was about five years. The corresponding time for gas turbines is much shorter. The Derwent $V$, for example, was designed and built and gave its full design power within four and a half months. Other firms have achieved similar results in about six months. So not only will the power plant and aircraft have to be made as a unified whole, but also design and development must proceed in parallel if years are not to be lost.

\section{AMINO-SUGARS AND URONIC ACIDS IN NATURE}

$T$ HE meetings organised periodically by the Biochemical Society, at which experts in a chosen field present short contributions designed as an intro. duction to a general discussion of the selected subject, have proved both popular and useful. The discussion held on February 16 on amino-sugars and uronic acids in Nature was no exception, bringing together as it did those interested in the more purely chemical problems of the constitution of the polysaccharides and those for whom the biological role of these most widely distributed substances is of primary interest.

The morning session, under the chairmanship of Prof. E. L. Hirst, was opened by Prof. Gunnar Blix of Uppsala, from whose laboratory much of our knowledge concerning these substances has emanated. Prof. Blix emphasized the wide distribution of the hexosamines and uronic acids in living structures and suggested that such ubiquity would alone suggest that they fulfil a role of importance. The long-chain polymers containing polysaccharide acids function in many situations as supporting or protecting gels. The newly shed ovum is surrounded by hyaluronic acid, the hydrolysis of which by the hyaluronidase of spermatozoa may be an important preliminary to fertilization. Hyaluronic acid and chondroitin sulphuric acid also function as cementing materials in the connective tissues, and alterations in these components have been found to be associated with pathological states. The invasiveness of pathogenic micro-organisms appears to be intimately connected with their production of the enzyme hyaluronidase. By reason of the high viscosity of solutions of the undegraded polysaccharide acid polymers, these substances are very suitable as biological lubricants and occur in synovial fluids. The interesting possibility that the pathological changes seen in infectious rheumatic disease and the hyaluronidase of the microbial invaders may be causally related is still an unanswered question, but clearly one of no little importance.

That the surfaces of mucous membranes may derive protection, particularly from proteolytic enzymes, by the mucoitin sulphuric acid and other mucins characteristically present in their secretions is an attractive hypothesis full of possibilities both in relation to normal physiology and to pathological changes. The method by which the polysaccharide sulphuric esters may be revealed histochemically was discussed by Prof. Blix, who pointed out the association of these materials with the process of growth in different tissues.

The neutral polysaccharides frequently occur in chemical combination with proteins, as, for example, 